\title{
Thermal Ionization Mass Spectrometry
}

National Cancer Institute

\section{Source}

National Cancer Institute. Thermal Ionization Mass Spectrometry. NCI Thesaurus. Code C158244.

A mass spectrometry method in which chemically-purified samples are heated to create positively ionized atoms that are then accelerated by an electric field and mass separated by an electromagnet. 